\title{
VIRTUDES JUDICIALES Y EMPATÍA
}

\author{
Judicial Virtues and Empathy
}

Luciana Samamé

(CIJS/UNC-CONICET, Argentina)

\begin{abstract}
Resumen
En este trabajo examino en sus rasgos característicos una tentativa muy reciente: la de incorporar centralmente el concepto de empatía en conexión con el de justicia para pensar las prácticas de los magistrados. Para ello reconstruyo las posiciones de dos referentes contemporáneos sobre la materia, Michael Slote y John Deigh, y muestro porqué sus planteos no resultan del todo satisfactorios. Es así que propongo a la perspectiva aristotélica como una vía de análisis mayormente fructífera, dado que consigue afrontar con mejor éxito las objeciones a las que una posición vindicatoria de la empatía está expuesta. Por lo demás, estos desarrollos se dan en el marco de una promisoria línea de análisis en filosofía jurídica: la llamada Virtue Jurisprudence, a la que también me referiré en este trabajo.
\end{abstract}

Palabras clave: Giro aretaico | Ética judicial | Emociones | Imparcialidad | Justicia.

\begin{abstract}
In this paper I examine in its main features a recent attempt in the domain of legal ethics, one that seeks to address the question of justice in relation with empathy. For this purpose, I reconstruct the positions of Michael Slote and John Deigh, aiming to show the kind of criticisms to which both of them are subject. Accordingly, I suggest that Aristotle's perspective is better equipped to confront those kinds of criticisms. Besides, all these developments and discussions are framed in a fruitful field of legal philosophy: the so-called Virtue Jurisprudence, to which I shall also refer in this article.
\end{abstract}

Keywords: Aretaic Turn | Legal Ethics | Emotions | Impartiality | Justice. 


\section{El giro aretaico en la filosofía moral y del derecho contemporáneas}

Desde el S. XVIII en adelante, las tendencias representadas por el deontologismo y el consecuencialismo llegan a dominar ampliamente las discusiones filosóficas éticas y jurídicas (Amaya, 2009: 13). Sin embargo, en la escena filosófica del S. XX empiezan a considerarse perspectivas limitadas e incompletas. Pues ambas se caracterizan por proponer un criterio simple de discriminación moral, un criterio que permita distinguir a un agente racional las acciones permitidas de las prohibidas, para luego guiar de manera segura su acción. Dichas teorías presumen centrarse así en el análisis de la acción antes que en el carácter del agente. En palabras de J. Annas (1993: 125), las mismas tienden generalmente a tomar como cuestiones primarias aquellas referentes a lo que uno debería hacer. En forma conexa, este tipo de teorías intenta proporcionar característicamente respuestas correctas a casos difíciles (Lariguet, 2011), de modo que de su aplicación a situaciones conflictivas puedan seguirse las decisiones acertadas. Por su parte, B. Williams (2006: 174) ha indicado que la moderna noción de "moralidad" se caracteriza por constituir un sistema de pensamiento donde el concepto de obligación exhibe el rol central, sugiriendo por lo demás que estaríamos mejor sin esa noción.

La índole insatisfactoria que para ciertos pensadores ostenta la "filosofía moral moderna”, consigue reactivar el interés, sobre todo en los últimos decenios del S. XX, por teorías que se presentan como alternativa a las figuradas por el consecuencialismo y el deontologismo respectivamente: las denominadas éticas de la virtud, cuyo resurgimiento trajo aparejada una afición renovada hacia las teorías antiguas. Éstas, antes que concentrarse en los principios de la buena o la mala acción, tienden a interesarse por delinear comprehensivamente los contornos de la vida buena (Striker, 1988: 183) Nuevamente a entender de Annas (1993: 4), las éticas antiguas no presuponen como conceptos básicos aquellos de "obligación", "deber", o "seguir una regla". En su lugar, emplean otra especie de categorías, tales como "bondad" o "valor", dado que sus intereses primarios se entretejen en derredor de las siguientes cuestiones: la formación del carácter y la práctica de las virtudes, el rol de las emociones y del razonamiento práctico, y todo ello bajo el telos fundamental que impulsa la especulación ética antigua, a saber: el logro de la eudaimonía, el bien supremo que hace a la vida humana satisfactoria y floreciente. Ciertos 
filósofos contemporáneos encuentran precisamente en esta clase de teoría, por el tipo de cuestiones que particularmente aborda, una opción más rica y fructífera: es así como en las postrimerías del S. XX se recupera el concepto de la vida buena en conexión con las virtudes morales (Vidiella y Guariglia, 2011: 197)

Lo precedentemente descrito nos proporciona un horizonte amplio de presupuestos donde es posible enmarcar el giro aretaico que asimismo emprende la filosofía jurídica. De manera semejante a MacIntyre en Tras la virtud (2004), quien describe la situación de la ética contemporánea con tintes pesimistas, Lawrence Solum hace lo propio con respecto a la filosofía del derecho: en su opinión, no sólo la teoría sino también la práctica jurídica contemporánea, se hallan en serios problemas (Solum, 2013: 3). Ello es así porque tanto el consecuencialismo como el deontologismo -tendencias también hegemónicas en aquéllano consiguen abordar satisfactoria ni íntegramente ciertas cuestiones, al desatender, por ejemplo, la relación entre el buen juzgar y las virtudes del juez, o la relación entre la ley y el carácter (Solum, 2003: 179) ${ }^{9}$

Como consecuencia, la Jurisprudencia de la virtud se propone en calidad de paradigma alternativo respecto del consecuencialismo y el deontologismo, ambicionando responder a las cuestiones clásicas de la teoría jurídica, aunque sin caer en la visión más bien fragmentaria o reduccionista de estas últimas, al tiempo que aboga por un cambio decisivo en las nociones básicas que aquélla debe emplear. Consiguientemente, y replicando una vez más lo que después de 1958 empieza a suceder en la esfera de la filosofía moral, la Virtue Jurisprudence plantea que los conceptos centrales de la teoría jurídica ya no serán los de "bienestar", "autonomía" o "eficiencia", sino los de virtud, excelencia, florecimiento humano (Solum, 2013: 2). Puede decirse que este viraje conceptual supone una mirada mayormente comprehensiva sobre los problemas clásicos de la filosofía del derecho, y que justamente por eso, involucra una ambiciosa tarea que aún se encuentra en estado programático. En referencia a tal situación, R. Duff (2003: 214) afirma que la emergencia de la Jurisprudencia de la virtud constituye uno de los rasgos más sobresalientes exhibido por la filosofía jurídica durante las últimas décadas, al contrastar notablemente con la perspectiva dominante asumida por el liberalismo. Por nombrar alguno de estos contrastes agudos, una de las tesis centrales de la primera, en

9 Amalia Amaya se hace eco también de una tesis de similar tenor: en su opinión, ni el consecuencialismo ni el deontologismo consiguen responder convincentemente a ciertas cuestiones que la filosofía jurídica debe afrontar, entre otras razones, por ser de difícil aplicación a casos concretos; fundamentalmente en relación con los “casos difíciles” o “casos trágicos” que un profesional del derecho debe dirimir (cf. Amaya, 2009:13-18) 
clara oposición al punto de vista asumido por aquel último, es que el objetivo de la ley es hacer virtuosos a los ciudadanos, buscando promover en tal dirección su florecimiento qua humanos.

\section{La Virtue Jurisprudence y el acento en las virtudes judiciales}

Conforme lo previamente delineado, la Virtue Jurisprudence se caracteriza por constituir un enfoque distintivo de la teoría jurídica normativa que se compromete con la asunción de tres tesis básicas -las cuales habilitan a la vez tres líneas de investigación bajo su rúbrica-: a) el propósito de la ley es auspiciar la excelencia del individuo y la de su comunidad, al crear las condiciones que permiten la práctica de las virtudes; b) el criterio de corrección legal en vistas a la resolución de conflictos, no puede establecerse independientemente del carácter del juez, y por tanto, de las virtudes judiciales; c) la naturaleza de la legalidad se comprende mejor si es entendida en cuanto internalización de las nomoi, y por extensión, como la disposición a su obediencia (Solum, 2013: 1-2).

En este trabajo me interesa abordar en forma exploratoria la segunda de estas líneas, a saber: la tesis según la cual tanto la explicación como justificación de la práctica de juzgar, requieren de la virtud en cuanto parte ineliminable (Solum, 2003: 201). En la actualidad, no son pocos los teóricos que adscriben esta perspectiva de análisis: se ha señalado, por ejemplo, que las teorías de la justicia tradicionales han dado mayor preponderancia a la cuestión del diseño adecuado de instituciones antes que a la cuestión de las personas justas (Lariguet, 2013: 114). En tal sentido, este enfoque centrado en el concepto de virtud, considera sumamente promisorio abordar la relación entre moralidad y derecho atendiendo al carácter de las personas que integran dichas instituciones. Por tal motivo parece indispensable hacer foco en las virtudes de los protagonistas que aplican el derecho, en este caso, los jueces.

Una de las versiones robustas de esta tesis es defendida precisamente por L. Solum, quien sostiene que el buen juzgar es una función de las virtudes del juez, de manera que se volverá una exigencia crucial la dilucidación de las virtudes judiciales. En esta dirección, el filósofo norteamericano abreva de fuentes aristotélicas, referencia fundamental y prácticamente obligada de los teóricos de la virtud contemporáneos. Para Aristóteles, las virtudes constituían disposiciones estables del carácter de una persona por las que ésta es 
capaz de obrar correctamente cada vez que las circunstancias lo requieren. De esta suerte, la evaluación moral de las acciones no puede divorciarse del carácter del agente que las ejecuta. $\mathrm{O}$ en otros términos, no puede existir un criterio de corrección de la acción independiente de las cualidades o virtudes del sujeto moral. En una tónica similar, Solum defiende la idea de que las virtudes del juez son condiciones de posibilidad -para emplear una expresión kantiana- de veredictos justos. Esto implica, asimismo, que la moralidad del juez no es externa a la institución del derecho.

Inspirado en el catálogo de excelencias morales e intelectuales que Aristóteles postula, Solum propone las siguientes virtudes en tanto notas distintivas e indispensables que un buen juez debe poseer: incorruptibilidad, coraje, sobriedad, inteligencia, sabiduría, las que encuentran al mismo tiempo unificación en la virtud cardinal de la justicia; pues si algo se presupone de un juez, es que es fundamentalmente justo. ${ }^{10}$ Ahora bien, una de las objeciones que esta concepción debe afrontar, es que el buen juzgar no depende de las virtudes del juez, sino simplemente de seguir un procedimiento correcto que garantice el resultado justo. Desde el punto de vista moral, es posible afirmar análogamente que una buena acción puede ser ejecutada por un agente no virtuoso, en la medida en que sea capaz de discriminar el proceso adecuado de deliberación para guiar la acción.

La concepción aretaica dispone de una estrategia central para afrontar la objeción recién planteada: la apelación a los casos difíciles, esto es, aquellos casos en que la ley es demasiado general como para guiarnos en el caso particular, o aquellos casos singularísimos en los que, de aplicarse la ley, se incurriría en una palmaria injusticia. Los defensores de la perspectiva centrada en las virtudes consideran que ni el deontologismo ni el consecuencialismo ofrecen fructíferas posibilidades de resolución, precisamente por ser incapaces de guiarnos en casos particulares. Por consiguiente, ante un caso difícil, es el juez virtuoso quien se encuentra en condiciones de ofrecer -all things considered- la mejor solución posible; pues este juez posee las virtudes judiciales: las excelencias intelectuales y morales que le permiten actuar sobresalientemente. Entre ellas, la sabiduría práctica o phrōnesis desempeña un papel central, por ser la virtud en especial referida al caso particular: la captación de los rasgos relevantes de una situación en función de los cuales se delibera y se arriba a una resolución acertada. Esta virtud -que para Aristóteles

10 Amalia Amaya también propone un catálogo análogo de virtudes judiciales: imparcialidad, sobriedad, valentía, sabiduría y justicia. Un interrogante que esta enumeración plantea y que aquí no podremos tratar, es si estas virtudes son propias de la función judicial y diferentes de las virtudes morales generales, o si son más bien especificaciones de estas últimas (cf. Amaya, 2009: 27-32) 
tenía un papel unificador, puesto que sin ella se es incapaz de ejercitar el resto de las virtudes- es especialmente sensible a los contextos: la enorme variabilidad en las circunstancias humanas, hace que una regla o principio general se revelen a veces impotentes para afrontar situaciones inéditas. Por tal razón, es esencial que un agente posea inteligencia práctica o la virtud de la prudencia.

Con todo, no es tan sencillo responder a la objeción previamente delineada. La misma ha generado y sigue generando serias controversias, a las que aquí no podré tratar adecuadamente. Sin embargo, puede plantearse que tal diferencia se remite en última instancia a una diferencia de enfoque. La filosofía moral moderna, de cuyos postulados esenciales se hace eco la filosofía jurídica, deja de lado la pretensión medieval y sobre todo antigua de formar agentes virtuosos en función del telos último de la vida buena. En la Modernidad, las cuestiones de justicia o estrictamente morales quedan divorciadas de ese telos. Es así como la filosofía moral moderna asumirá una pretensión de más modesto alcance: la tematización de la vida humana, no ya como un todo, sino desde una perspectiva más bien fragmentaria, en clara sintonía con el espíritu diseccionador de la ciencia moderna. Entonces, ya no se tratará tanto de la formación íntegra de los seres humanos según sus fines más propios, sino preferentemente de regular sus acciones de modo tal que sus derechos no resulten vulnerados.

Es plausible sostener así que esta mirada típicamente moderna y que actuales teorías jurídico-morales recogen, es parcial o incompleta, ya que con ella hay algo que se pierde, a saber: la complejidad y al mismo tiempo riqueza de los fenómenos humanos. Para seguir con la semejanza que se ha trazado: así como sólo artificialmente puede separarse una acción de la persona que la realiza, sólo artificialmente también puede escindirse una decisión judicial del juez que la enuncia. Quizá sea esta una buena razón para adherir a la alternativa que las teorías basadas en la virtud ofrecen, porque ciertamente intentan recuperar esa mirada más comprehensiva que no desatiende las dimensiones plurales que concurren en todo hecho humano. Por lo tanto, el enfoque basado en las virtudes en cuanto complemento adecuado de una teoría de la argumentación jurídica, parece ofrecer una rica perspectiva de análisis. 


\section{La empatía y la jurisprudencia: desafíos y posibles vías para afrontarlos.}

Es propio de los teóricos de la virtud abordar a la justicia como una virtud de carácter. En términos simplistas, tal cosa puede expresarse de la siguiente forma: la justicia es la disposición estable del carácter por la que una persona se ve llevada siempre -o toda vez que las circunstancias lo permiten- a obrar justamente. Ahora bien, Aristóteles decía que la virtud ética está referida a acciones y pasiones (EN 1106b 18- 20); ello significa que una acción virtuosa no es solamente tal por realizarse de cierta manera -justa o sobriamente-, sino además porque quien la realiza se encuentra en cierta disposición al hacerla (EN 1105a 28-32). Lo que Aristóteles presuntamente quiere decir es que ser virtuoso requiere más que el simple obrar correcto: requiere también de la posesión de emociones adecuadas. En este sentido, por ejemplo, un agente que exhibe una fácil y desmedida tendencia hacia la ira, probablemente muestre dificultades en deliberar correctamente y obrar con justicia si no es capaz de templar su cólera. Desde la perspectiva aristotélica se evidencia claramente, luego, que la moralidad rebasa la mera corrección de la acción. ${ }^{11}$

La visión comprehensiva que Aristóteles mantiene respecto de la virtud -dado que abarca acciones y pasiones- confiere un marco adecuado para plantear la cuestión que aquí particularmente nos incumbe: pues ciertos autores contemporáneos han planteado en forma muy reciente la conexión entre justicia y empatía. Para ponerlo en términos aristotélicos: una persona es justa no solamente por realizar acciones justas, sino además por hacerlo a partir de cierta disposición anímica, en este caso, empática. La idea de que las virtudes no pueden estar desconectadas de determinadas emociones, ha conducido a pensar, por tanto, que una concepción adecuada de la justicia no debería prescindir de la categoría de "empatía". Dado que el presente trabajo se contextualiza en la discusión de las virtudes judiciales, lo que aquí se coloca en el centro de la escena, es la cuestión de las prácticas empáticas por parte de un juez. Es así como hay quienes se atreven a afirmar aunque con diferentes matices- que es necesario que los jueces posean empatía, porque

11 Luego el fin primordial de la teoría ética no apunta a establecer un criterio de corrección moral -aquel que permite distinguir entre acciones lícitas e ilícitas- sino a dilucidar la naturaleza de las virtudes que un sujeto moral debe poseer y el modo en que éste puede alcanzarlas. Asimismo, el agente virtuoso es el único capaz de experimentar una vida plenamente satisfactoria, precisamente por hacerse asequible a través de la práctica de las virtudes el bien supremo, a saber: la eudaimonía o felicidad. 
sin ella, difícilmente arribarían a veredictos justos.

Antes de abordar los problemas que dicho posicionamiento implica, es menester aclarar qué debe entenderse por "empatía". El hecho de que actualmente se trate de un término tan en boga, ha contribuido a oscurecer su sentido -afirma por ejemplo J. Deigh (2011: 74) -; inclusive pueden reconocerse una serie de significaciones diferentes con las que ha estado asociado el término (Brunstein, 2015: 17-19). Con todo, los autores que abordan la cuestión de la empatía en conexión con la jurisprudencia, toman como punto de partida - hasta donde he podido rastrear- alguno de los dos sentidos en que la empatía es definida por el psicólogo norteamericano Martin Hoffman. En opinión de este último, el concepto refiere tanto a: 1) la aprehensión cognitiva de los pensamientos, sentimientos, percepciones e intenciones de otros sujetos, como a b) la respuesta afectiva a otra persona (Hoffman, 2001: 29-30). Como se verá luego, estas dos dimensiones -cognitiva y afectivacrearán ciertas tensiones en las propuestas de los autores, según sea enfatizado uno u otro sentido.

Delineadas estas nociones preliminares, quizá la primera objeción que debe enfrentarse es la de quien aduce que la noción de empatía en el ámbito de la ética jurídica resulta superflua. En efecto, con todo derecho podría plantearse que en tanto "empatía" resulta un concepto aceptable -digamos- en el dominio de la moralidad general, no resultaría viable ni heurísticamente potente para pensar la moralidad de rol. En consecuencia, alguien podría aducir que desde un punto de vista moral general, es deseable y loable el que una persona exhiba empatía en cuanto cualidad de su carácter, pero que, no obstante, no tendría por qué ser requerida en lo que atañe al rol profesional, en este caso, al juez en funciones. Ello es así porque todo lo que se requiere de un juez para actuar correctamente es que éste interprete y aplique correctamente la ley, y en este sentido, es difícil ver que a la empatía le quepa rol alguno. Si esta objeción es correcta, no habría razones para considerar a la empatía como categoría de análisis necesaria en la jurisprudencia, tratándose entonces de un concepto superfluo.

Una estrategia admisible para enfrentar esta objeción podría ser la siguiente: planteando que la moralidad no puede ser entendida en forma fragmentaria, esto es, como un conjunto no homogéneo o contrapuesto de obligaciones. Para quien comparte esta visión de la moralidad, existirían virtudes morales generales y virtudes específicas 
atinentes al rol, de manera que no habría continuidad entre las primeras y las segundas. ${ }^{12}$ De esta visión se desprende que un tipo de conducta comúnmente considerado reprobable, podría no serlo en el contexto del ejercicio de una profesión particular. ${ }^{13}$ Si bien esta posición es defendible y ameritaría un debate más extenso que no estoy en condiciones de ofrecer, la considero en principio contraintuitiva ${ }^{14}$ y relativista ${ }^{15}$. Esto me lleva a explicitar el punto de partida que adoptaré y las tesis que, en consecuencia, estoy dispuesta a defender: 1) la empatía configura un rasgo moral en los seres humanos y se trata de un aspecto esencial inherente a la virtud ética $\left.{ }^{16} ; 2\right)$ dado que el ejercicio de un rol no puede divorciarse a mi parecer de los requerimientos de la moralidad general, es deseable que un profesional o funcionario no carezca de empatía.

Explicitada esta estrategia por la cual sería posible hacer frente a la objeción de la superfluidad de la empatía, pasemos a la segunda -tal vez más grave y de difícil resolución-, a saber: que la empatía puede atentar contra la imparcialidad ${ }^{17}$, la virtud por antonomasia del buen juez. Así, el objetor sugeriría que un juez movido por la empatía podría dictar sentencias injustas, precisamente por empatizar demasiado con alguna de las partes. Es plausible que tal cosa, v.g., le lleve a mitigar indebidamente la pena a un criminal producto de la conmoción que le ha provocado conocer su historia de vida. Antes de delinear alguna estrategia que permita encarar esta objeción, quizá sea conveniente comenzar refiriendo la posición de una de las figuras más representativas que encarnan la defensa de la empatía en el marco de la jurisprudencia: Michael Slote. Este autor pretende fundamentar nociones básicas como las de justicia social y legal sobre bases sentimentalistas, en el marco de una ética de la virtud. ${ }^{18} \mathrm{~A}$

12 Estoy simplificando muchísimo esta posición -la cual admite matices- en virtud del argumento que deseo defender.

13 Para poner un ejemplo ilustrativo aducido por A. Amaya: la falta de empatía o la rudeza podrían ser virtudes de un empresario, mientras que estas mismas cualidades no se juzgan favorablemente desde el punto de vista moral general, al ser reconocidas más bien en calidad de vicios o defectos.

14 Me resulta contra-intuitivo pensar que una cosa es la moral que debería guiar los asuntos humanos en general, y otra diferente, la moral que habría de regir las profesiones. Esto conllevaría, asimismo, una multiplicación exponencial de las moralidades.

15 La idea de que algo puede ser bueno o correcto en un contexto, pero no puede serlo en otro, entraña una forma de relativismo, a saber: que la noción de "bueno" o “correcto” no puede ser establecida independientemente de los contextos, con base en criterios universales.

16 Una cuestión que me interesa centralmente es la virtud de la compasión y su conexión con la empatía (ambos conceptos, si bien suele diferenciárselos, están estrechamente conectados), algo que por el momento eludiré pero que trataré en trabajos futuros.

17 Una forma con la que suele revestirse este supuesto antagonismo entre empatía e imparcialidad, es que mientras la primera está orientada hacia lo particular, la segunda en cambio lo está hacia lo universal.

18 En opinión de Martha Nussbaum (1999), la ética de la virtud contemporánea alberga dos grandes orientaciones que, si bien comparten un núcleo de preocupaciones comunes, son manifiestamente divergentes: la anti-kantiana y 
contrapelo de lo que suele pensarse, el filósofo norteamericano sostiene que los jueces han de ser capaces de experimentar empatía para presidir juicios justos y proporcionar veredictos imparciales. El criterio general subyacente a esta concepción es el siguiente: las leyes, instituciones y costumbres son justas si y sólo si aquellos que las promulgan, mantienen o participan en ellas, no carecen de concernimiento empático hacia las personas o grupos de personas a las que las primeras envuelven y afectan (Slote, 2013: 282).

Ahora bien, el problema vuelve a recaer en cómo debe entenderse, en tal contexto, la empatía. Recordemos que no se trata de una noción precisamente diáfana o unívoca. Slote sostiene que la empatía involucra una especie de unidad -oneness- e identificación con los otros. De esta suerte, cuando alguien dice por ejemplo "siento tu dolor", es indicativo de la presencia de este tipo de emoción (Ibíd.: 281). Luego una nota distintiva de la empatía, parece ser la sensibilidad específica hacia el infortunio o sufrimiento que aqueja a otros seres -ya sean cercanos o bien lejanos a nosotros, tanto espacial como temporalmente-. En esta tónica, Slote asevera que la empatía se sitúa muy cerca de la compasión. Ello es así porque tendemos a empatizar mayormente con aquellos que han caído en desgracia o atraviesan una mala situación. Por otra parte, y según este autor, la moralidad descansa exactamente en la capacidad de experimentar empatía hacia nuestros congéneres. Es bajo tales premisas que Slote llega a decir que las leyes e instituciones no deberían reflejar una falta de compasión -a lack of compassion- (Ibíd.: 287).

Planteemos nuevamente la objeción que una posición vindicatoria de la empatía debe afrontar: el riesgo que ello entraña para la práctica de la justicia y la imparcialidad. Consciente de este problema, Slote dispone de una interesante estrategia defensiva ante el objetor: un juez que aplicara un castigo débil -como en el ejemplo más arriba mencionado- mostraría por un lado una gran empatía hacia el convicto, pero su conducta evidenciaría por el otro, una falta de empatía hacia aquellos afectados por la conducta del criminal o hacia aquellos que potencialmente podrían serlo en el futuro (Ibíd.: 288)

la anti-utilitarista. En tanto estos últimos encuentran inspiración en la ética aristotélica y pueden incluso desear un acercamiento con Kant, la orientación anti-kantiana encuentra inspiración, en cambio, en Hume, Hutcheson y, en general, en la tradición de los sentimientos morales. Slote pertenece decididamente a la serie de autores críticos de la tradición kantiana y racionalista en ética. En este sentido, Rosalind Hursthouse (2013) señala que la desviación más radical de la tradición ética antigua, se encuentra representada en Michael Slote, cuyo posicionamiento abreva de Hume, Hutcheson, Martineau y la ética feminista del cuidado. 
A pesar de visibilizar un agudo contrapunto, la respuesta de Slote no resulta enteramente satisfactoria: mi impresión es que su posicionamiento no nos ofrece, en definitiva, un criterio normativo que permita orientar la disposición empática sin que ello actúe en detrimento de la imparcialidad. Si bien nos sugiere, a partir de su conceptualización, que la empatía judicial -si se me permite esta expresión- debe ser ejercida de manera equilibrada, esto es, teniendo en cuenta a todas las partes involucradas, no nos dice con base en qué pauta hacerlo. ${ }^{19} \mathrm{Su}$ argumento es más bien de calibre descriptivo: pues simplemente nos dice que un juez actúa justamente cuando exhibe una actitud empática no parcial, esto es, armónicamente direccionada hacia todos los posibles afectados. De esta manera, la tentativa de Slote parece enmarcarse más bien en la psicología moral antes que en la ética normativa.

A juicio de John Deigh (2013: 293), el problema con la posición de Slote es que privilegia en demasía la dimensión afectiva en su interpretación de la empatía, cosa que va enteramente de la mano con su visión sentimentalista del fundamento moral. Para diferenciar su posición de la de aquél, Deigh defiende una acepción puramente cognitiva de empatía: el estado en virtud del cual nos volvemos conscientes de los pensamientos, sentimientos, percepciones e intenciones de otras personas (Deigh, 2011: 74). Dada esta definición, lo que resulta esencial a la empatía es la capacidad de comprender diferentes perspectivas o puntos de vista. A entender de este autor, la empatía es también esencial para la moralidad: si no fuéramos capaces de adoptar la perspectiva de otros, no nos sería posible cooperar mutuamente. ${ }^{20}$ Concebida en esta dirección, la empatía desempeña según Deigh un rol crucial aunque no reconocido, en la ética de varios filósofos racionalistas, inclusive en Kant (Ibíd.: 75).

Teniendo en cuenta lo anteriormente señalado, la tesis fuerte defendida por Deigh con relación al rol de la empatía en la jurisprudencia es la siguiente: una interpretación sólida de la ley requiere de la empatía. Pues se debe ser sensible a las perspectivas de las diferentes personas cuyos intereses son afectados por la ley o pueden llegar a serlo en caso

19 Dado su alejamiento de la tradición racionalista, tal como se ha advertido con anterioridad (nota al pie $\mathrm{N}^{\mathrm{o}} 10$ ), Slote no menciona en sus discusiones a la virtud de la phronesis o sabiduría práctica. Según R. Hursthouse (2013), sin embargo, tal cosa debe suponerse para que su concepción sobre la motivación moral resulte inteligible, esto es, la proclama según la cual los motivos virtuosos deben tomar en cuenta al mundo y ser balanceados.

20 John Deigh toma como base de sus análisis la concepción piagetiana sobre el desarrollo moral en los niños. Según esta visión, la evolución moral consiste en dejar de ver a las reglas como normas rígidas e incuestionables para pasar a concebirlas como el producto de una empresa cooperativa, donde las reglas son acordadas y están abiertas al cuestionamiento y la variación. Este tránsito en el que se entrevé la maduración moral del sujeto, iría de una “moralidad de la coacción” a una “moralidad de la cooperación”. 
de que ésta sea aplicada a su situación. Cuando la ley, por el contrario, es interpretada a partir de una ausencia de empatía hacia los afectados o eventuales afectados, cuando la ley se aplica sobre la base de una lectura "estricta" ${ }^{21}$, luego es muy probable que el resultado sea injusto. ${ }^{22}$

Podría decirse que la postura de Deigh posee un gran atractivo, ya que parece eludir el riesgo que una interpretación puramente afectiva conlleva: es decir, si la empatía alude a un estado cognitivo, no habría razones para temer su presunta amenaza contra la imparcialidad. Más bien lo contrario: así entendida, la empatía sería la condición de posibilidad de la imparcialidad. Bajo esta luz es plausible afirmar que, la imparcialidad de las sentencias judiciales depende de que el juez haya considerado previamente y en forma equilibrada, todas las perspectivas de los actores involucrados en el caso. En este sentido, la destreza para considerar diferentes perspectivas, semeja constituir incontestablemente parte esencial de la labor de los jueces.

Con todo el atractivo que pueda poseer, la propuesta de Deigh presenta un problema en principio conceptual, el cual se manifiesta en su manera de entender la empatía: definirla en términos enteramente cognitivos parece ser una contradicción en los términos (Brunstein, 2015: 22). Ello es así porque es imposible eludir el hecho de que "empatía” se configura primordialmente a partir del vocablo griego pathos. Éste refiere a la capacidad de ser afectado, a la capacidad de sentir y padecer. La empatía posee luego una dimensión afectiva que, mal que a Deigh le pese, debe ser reconocida; de lo contrario, ya no estaríamos frente a ella, sino a un fenómeno de naturaleza desemejante.

Las dificultades con que tropiezan tanto una interpretación exclusivamente cognitivista como emotivista de la empatía, conducen a pensar que es necesario plantear una concepción que integre ambos aspectos. ${ }^{23}$ La empatía presume tratarse de un fenómeno complejo que envuelve a un tiempo rasgos perceptuales y emotivos que difícilmente podemos separar. Por ejemplo, la disposición afectiva por la que tendemos a

21 Por "lectura estricta" debe entenderse en este contexto, aquellas interpretaciones exclusivamente apegadas a la letra de la ley o fundamentalmente preocupadas por identificar cuál es la regla implícita en la jurisprudencia precedente para aplicar al caso presente.

22 Para ejemplificar su posición, John Deigh (2011) analiza en detalle el caso de Lilly Ledbetter, un caso que podría considerarse "difícil" y que llegó hasta la Corte Suprema de los Estados Unidos. Deigh analiza, en efecto, el fallo dividido que el caso obtuvo, mostrando cómo el veredicto que se impuso fue injusto por evidenciar una falta de empatía hacia la perspectiva de la acusada; el fallo disidente, en cambio, ejemplificaba el modo en que la empatía posee un rol eminente dentro de la jurisprudencia.

23 A raíz de los aspectos objetables que P. Brunstein encuentra en la concepción de John Deigh, propone en su artículo una "concepción interdisciplinaria e integral de empatía”, en donde no se vislumbre una separación tajante entre aspectos cognitivos y emotivos (Cf. Brunstein, 2015: 27) 
ayudar a quien está en peligro, debe envolver a la vez la percepción de que efectivamente se encuentra en peligro. Quizá las perspectivas un tanto sesgadas que tanto Slote como Deigh nos ofrecen, se explican en cierta medida por la influencia decisiva de Hume sobre el primero y de Kant sobre el segundo. En términos un tanto reduccionistas, el problema que sus respectivas concepciones de empatía poseen, refleja el problema que a las teorías éticas sentimentalistas o puramente racionalistas se les plantea: a la primera suele reprochársele su irracionalismo -dado el antagonismo que presenta entre razón y pasión, y el predominio de la segunda sobre la primera-; al racionalismo suele reprochársele una visión poco realista de la condición humana, justamente por dejar fuera de su marco conceptual a las emociones.

Dadas estas limitaciones, la visión aristotélica parece estar mejor equipada para proveernos de una concepción mayormente adecuada -esto es, integral- de empatía. Recordemos su afirmación conforme con la cual las virtudes éticas están referidas tanto a acciones como a pasiones. Una acción es justa no sólo por estar realizada de cierta manera sino también por serlo a partir de cierta disposición. Con el marco conceptual aristotélico puede proponerse luego, a título exploratorio, entender a la empatía como el correlato emocional de la virtud de la justicia. Por otra parte, para este enfoque es perfectamente compatible sostener a un tiempo la relevancia decisiva de las emociones morales junto con el papel regente de la razón. De hecho, es la razón quien regula las emociones: hay respuestas emocionales apropiadas e inapropiadas, siendo aquélla la única capaz de determinarlo. Desde el punto de vista aristotélico, en efecto, las emociones son permeables a la razón y se dejan modelar por ella; en consecuencia, es posible una educación sentimental.

En la óptica del estagirita, el agente virtuoso sabe cómo actuar en el momento oportuno por las razones correctas y desde una disposición recta. Si trasladamos este esquema conceptual a la práctica judicial, puede decirse que un juez virtuoso es aquel que delibera correctamente y arriba a una sentencia justa, haciendo todo esto, además, desde una disposición emocional adecuada. Dada asimismo la teoría aristotélica del justo medio, un juez no debería ser ni demasiado empático ni traslucir en su conducta una falta de empatía. Ahora bien, queda todavía sin resolver la cuestión relativa a la imparcialidad, esto es, de qué modo le es posible a la empatía no interferir con ella. A este respecto, creo que la perspectiva aristotélica nos coloca en las vías adecuadas para proporcionar una respuesta 
satisfactoria. Y ello por dos razones: porque su concepción de virtud habilita la incorporación de una noción integral de empatía -donde confluyen los aspectos emotivos y cognitivos- y porque su teoría ética nos provee de un fundamento racional, lo cual se trasluce en el esquema de las virtudes a partir de la centralidad que la virtud de la phrōnesis o inteligencia práctica posee.

Es consabida la relevancia y centralidad que esta virtud intelectual posee en el horizonte de la teoría aristotélica, dado su papel unificador: sin phrōnesis las llamadas virtudes éticas o del carácter -entre las que Aristóteles cuenta a la virtud de la justicia- no encontrarían un cauce adecuado de aplicación. Tal como Linda Zagzebski (1996: 240) ha señalado, la phrōnesis posee tres funciones características: la determinación del justo medio; la de mediar entre virtudes que hacen demandas contrapuestas; la percepción de los rasgos relevantes del caso concreto en vistas de su resolución. Dadas estas características, salta por sí misma a la vista la importancia de esta virtud para el ejercicio de la judicatura. Si la inteligencia práctica es capaz de modelar las emociones -tal como la concepción aristotélica reconoce-, entonces no habría motivos para suponer que, una vez admitida la entrada de las emociones, el sujeto perdería su capacidad de control y manejo. ${ }^{24}$ En el caso que aquí nos ocupa, no habría razones para temer que un juez con la virtud intelectual de la phrōnesis, pudiera ceder a emociones inapropiadas -por ejemplo aminorando una pena por ceder en exceso a su inclinación empática hacia el convicto ${ }^{25}-$.

Quisiera finalizar con la mención de una fina observación realizada por Arleen Salles, la cual nos provee de una pista -en mi opinión acertada- para resolver el aparente conflicto entre emoción e imparcialidad. A juicio de la autora, se suele contraponer la imparcialidad a la emoción bajo la premisa de que la primera se sustrae o está exenta de la segunda. Se piensa así que la parcialidad -típicamente suscitada por la emociónconstituye la contracara de la imparcialidad, incólume e impertérrita frente a la amenaza representada por aquélla. Sin embargo -nos dice Salles (1999:221) -, no es necesario pensar a la imparcialidad como a "una actitud de indiferencia, desinterés y desapego". Pues quien se siente motivado a obrar con imparcialidad, no lo hace precisamente en

24 En opinión de Arleen Salles (1999: 220), una de las razones aducidas por quienes se niegan a conceder un rol protagónico a las emociones dentro de la moralidad, reside en nuestra pasividad respecto de las mismas: no podemos controlar las emociones, y por tal motivo no somos responsables frente a ellas. La visión aristotélica desafía manifiestamente semejante tesitura.

25 En el otro extremo -tratándose igualmente de una práctica viciosa, según la teoría aristotélica del justo medio- se ubicaría el caso del juez que, por carecer de empatía, procuraría por todos los medios endurecer al máximo una condena. 
virtud de su indiferencia; muy por el contrario, lo hace porque le importan y movilizan la justicia y los derechos de los demás. Desde esta óptica, lo que caracterizaría a una persona imparcial y justa es su apego hacia fines moral o jurídicamente deseables. Si ello es así, entonces la emoción sería constitutiva de la imparcialidad.

\section{A modo de cierre}

He comenzado refiriéndome en este trabajo al giro aretaico que la filosofía del derecho emprendió en los últimos decenios del Siglo XX. He intentado evidenciar su parentesco directo con la ética de la virtud y de qué manera este último concepto se vierte al ámbito jurídico. En especial, hice alusión a la llamada Virtue Jurisprudence, una promisoria y reciente línea de investigación en filosofía del derecho que, entre sus principales pretensiones, se propone tematizar las virtudes judiciales. Alineándome con este enfoque, he propuesto pensar a la justicia en conexión con el concepto de empatía, reconstruyendo algunas de las principales posiciones actuales al respecto, a saber: la de Michael Slote y la de John Deigh. Siendo valiosísimos los aportes de estos autores, he procurado mostrar que, con todo, sus planteos adolecen de ciertas flaquezas, debidas sobre todo a sus concepciones un tanto unilaterales de empatía. En compensación, he sugerido que Aristóteles nos provee de una concepción integral y de un tipo de teoría ética más adecuada para enfrentar las objeciones que se suelen dirigir a quienes avalan la incorporación de las emociones tanto en el terreno moral como jurídico.

Se ha visto que una cuestión especialmente acuciante, es la de cómo hacer para que la empatía no erosione la imparcialidad, virtud por antonomasia del buen juez. Según se ha intentado mostrar, no solo se puede hacer frente a este reparo sino incluso desmantelarlo a partir de estos presupuestos: 1) un juez prudente -aquel con sabiduría práctica-, difícilmente se vea desbordado por sus emociones, ya que éstas han sido modeladas por su razón; esto nos permite postular que, al darse tales condiciones, el mismo es capaz de actuar con base en una disposición empática recta; 2) la imparcialidad involucra en un importante sentido a la emoción, porque la actitud por la que nos vemos llevados a considerar equitativamente nuestros intereses y los de los demás, lejos de tratarse de una actitud fría y desapegada, está henchida de estima hacia la justicia y los fines moralmente deseables. Es probable que estas aproximaciones no resulten para algunos enteramente 
convincentes. No obstante, considero que nos colocan al menos en las vías adecuadas para seguir pensando y profundizando la conexión entre empatía y justicia, cuestión sobre la que resta aún mucho por hacerse, dada su muy reciente tematización en el dominio de la ética judicial.

\section{Referencias bibliográficas}

AMAYA, Amalia. (2009). Virtudes Judiciales y Argumentación. Una aproximación a la ética jurídica. México: Tribunal Electoral del Poder Judicial de la Federación.

ANNAS, Julia. (1993). The Morality of Happiness. New York: Oxford University Press. ARISTÓTELES. (1997). Ética Nicomáquea. Barcelona: Altaya.

BRUNSTEIN, Patricia. (2015). "El rol de la empatía en la jurisprudencia desde la óptica de J. Deigh. Un análisis crítico a partir del caso Lilly Ledbetter”. Nuevas Fronteras de Fỉlosofía Práctica, Número 4, pp. 17-19.

DEIGH, John. (2011). "Empathy, Justice and Jurisprudence”. The Southern Journal of Philosophy, Volume 49.

DEIGH, John. (2013). "Empathy in Law (A Response to Slote)". En Law, Virtue and Justice (eds. A. Amaya y H. Hock Lai). Oxford: Hart Publishing.

DUFF, R.A. (2003). “The Limits of Virtue Jurisprudence”, Metaphilosophy 34.

HOFFMAN, Martin. (2001). Empathy and Moral Development. Cambridge: Cambridge University Press.

HURSTHOUSE, Rosalind. (2013). "Virtue Ethics". En The Standford Encyclopedia for Philosophy. Disponible en: http://plato.stanford.edu/entries/ethics-virtue

LARIGUET, Guillermo. (2011). Encrucijadas Morales. Una aproximación a los dilemas y su impacto en el razonamiento práctico. Madrid-México: Plaza y Valdez Editores.

LARIGUET, Guillermo. (2013). “El aguijón de Aristófanes y la moralidad de los jueces”. Doxa. Cuadernos de Filosofía del Derecho 36.

MACINTYRE, Alasdair. (2004). Tras la Virtud. Barcelona: Crítica.

NUSSBAUM, Martha. (1999). "La ética de la virtud: una categoría equívoca”. ARETÉ. Revista de Filosofía, Vol. XI, No 1-2, pp. 573-613

SALLES, Arleen. (1999). "Percepción y Emociones en la Moralidad”. Isegoría. Revista de Filosofía Moral y Política $\mathrm{N}^{\circ} 20$. 
SLOTE, Michael. (2013). "Empathy, Law and Justice". En Law, Virtue and Justice (eds. A. Amaya y H. Hock Lai). Oxford: Hart Publishing.

SOLUM, Lawrence. (2013). "Virtue Jurisprudence. Towards an Aretaic Theory of Law". En Aristotle and the Philosophy of Law: Theory, Practice and Justice. Ius Gentium: Comparative Perspectives on Law and Justice 23 (eds. Huppes-Cluysenaer y Cohelo). London-New York: Springer.

SOLUM, Lawrence. (2003). "Virtue Jurisprudence. A virtue-centred theory of judging". Metaphilosophy 34. 